\title{
The effect of increased lipid intake on hormonal responses during aerobic exercise in endurance-trained men
}

\author{
Emanuel R Christ, Monica Zehnder ${ }^{1}$, Chris Boesch ${ }^{1}$, Roman Trepp, Primus E Mullis ${ }^{2}$, Peter Diem and \\ Jacques Décombaz ${ }^{3}$ \\ Divisions of Endocrinology and Diabetes, ${ }^{1}$ Clinical Research and ${ }^{2}$ Paediatrics, University Hospital of Berne, Inselspital, CH-3010 Bern, Switzerland and \\ ${ }^{3}$ Nestlé Research Centre, Nestec Ltd, Lausanne, Switzerland \\ (Correspondence should be addressed to E R Christ; Email: emanuel.christ@insel.ch)
}

\begin{abstract}
In view of the growing health problem associated with obesity, clarification of the regulation of energy homeostasis is important. Peripheral signals, such as ghrelin and leptin, have been shown to influence energy homeostasis. Nutrients and physical exercise, in turn, influence hormone levels. Data on the hormonal response to physical exercise (standardized negative energy balance) after high-fat (HF) or low-fat (LF) diet with identical carbohydrate intake are currently not available. The aim of the study was to investigate whether a short-term dietary intervention with HF and LF affects ghrelin and leptin levels and their modulators, GH, insulin and cortisol, before and during aerobic exercise. Eleven healthy, endurance-trained male athletes $\left(W_{\max } 365 \pm 29 \mathrm{~W}\right)$ were investigated twice in a randomized crossover design following two types of diet: 1 . LF - $0.5 \mathrm{~g}$ fat $/ \mathrm{kg}$ body weight (BW) per day for 2.5 days; 2 . HF - $0.5 \mathrm{~g}$ fat $/ \mathrm{kg} \mathrm{BW}$ per day for 1 day followed by $3.5 \mathrm{~g}$ fat $/ \mathrm{kg}$ BW per day for 1.5 days. After a standardized carbohydrate snack in the morning, metabolites and hormones $(\mathrm{GH}$, ghrelin, leptin, insulin and cortisol) were measured before and at regular intervals throughout a 3-h aerobic exercise test on a cycloergometer at $50 \%$ of $W_{\text {max }}$. Diet did not significantly affect GH and cortisol concentrations during exercise but resulted in a significant increase in ghrelin and decrease in leptin concentrations after LF compared with HF diet (area under the curve (AUC) ghrelin LF vs HF: $P<0.03$; AUC leptin LF vs HF: $P<0.02$, Wilcoxon rank test). These data suggest that acute negative energy balance induced by exercise elicits a hormonal response with opposite changes of ghrelin and leptin. In addition, the hormonal response is modulated by the preceding intake of fat.
\end{abstract}

European Journal of Endocrinology 154 397-403

\section{Introduction}

Obesity with its associated complications, such as metabolic syndrome and type 2 diabetes, is a rapidly growing health problem $(1,2)$. There has been substantial effort in uncovering the regulation of energy homeostasis. A particular focus of this research is the impact of peripheral signals, such as ghrelin (3) and leptin (4), which have been associated with appetite-regulating responses at the hypothalamic and pituitary levels (5). Leptin, secreted by white adipose tissue, decreases food intake (5), whereas ghrelin, mainly produced in the stomach, has an orexigenic function. In addition, ghrelin is a potent secretagogue of growth hormone (GH) in animals (6) and man (7). A standardized aerobic exercise protocol can be considered as a transitory condition of negative energy balance eliciting a defined hormonal response in order to compensate for energy expenditure. In man, it has been shown that short-term exercise $(1 \mathrm{~h})$ at high intensity $\left(80 \%>V \mathrm{O}_{2 \max }\right)$ does not affect leptin levels in healthy subjects $(8,9)$, but long-term exercise $(2 \mathrm{~h})$ leads to a reduction in leptin levels $(10,11)$. It is well established that growth hormone $(\mathrm{GH})$ secretion increases during exercise (12) and depends on exercise intensity $(13-16)$, duration $(17,18)$, age and training status (19). Whether ghrelin is the main physiologic secretory stimulus of $\mathrm{GH}$ is debated: recent evidence suggests that ghrelin is not involved in the exercise-induced stimulation of $\mathrm{GH}$ secretion during a submaximal aerobic exercise (20), whereas it has been suggested that the preprandial increase in ghrelin levels drives the GH surge postprandially (21). Besides hormones, nutrients may be peripheral signals involved in energy homeostasis (22). There is evidence that insulin-mediated glucose metabolism stimulates 
leptin production, resulting in a decrease in the signal for appetite at the hypothalamus (22). The effect of a high-fat (HF) diet on leptin concentrations is controversial: HF diet did not significantly affect fasting leptin levels (23), whereas the 24-h leptin profile during HF combined with a low-carbohydrate diet showed a significant reduction in leptin levels (24), possibly mediated by a decrease in insulin secretion. The high levels of ghrelin expression in the stomach suggest that nutritional factors may be involved in regulating ghrelin secretion (3). This hypothesis has been supported by the observation that weight loss induced by caloric restriction increased ghrelin concentrations, whereas gastric bypass surgery in obese patients resulted in unchanged ghrelin levels after weight loss (25). Data on the influence of different nutrients on ghrelin are scarce. An acute oral glucose (26) or lipid (27) load has been shown to decrease ghrelin concentrations in healthy volunteers, whereas a protein load did not affect ghrelin concentrations (27).

We assume that energy balance is tightly regulated by peripheral signals, including nutrients and hormones. It is, therefore, hypothesized that dissimilar lipid intake will have an opposite impact on ghrelin and leptin as well as their possible modulators, insulin and cortisol levels, during a standardized exercise protocol. Thus, hormone levels and metabolites were investigated in endurance-trained male athletes during a 3-h aerobic exercise after HF and low-fat (LF) diet in a randomized, crossover design. Importantly, carbohydrate and protein intake was identical in both diets. Endurance-trained male athletes were chosen in order to investigate a homogeneous study population without possible gender-specific (28) or training-related confounding factors of hormonal response (29).

\section{Materials and methods}

\section{Subjects}

Eleven healthy, endurance-trained male athletes (road or cross-country cyclists, duathletes and triathletes) were recruited. A minimum of $3 \mathrm{~h}$ of training per week and an aerobic capacity of $\geq 60 \mathrm{ml} / \mathrm{min}$ per $\mathrm{kg}$ body weight $(\mathrm{BW})$ were required for participation in this trial. Smokers and regular users of drugs or alcohol $(>30 \mathrm{~g}$ alcohol/day) were not included. Subjects who did not comply with the diet instruction were excluded. All subjects provided informed, written consent, and the study was approved by the ethics committee of the Kanton Berne, Switzerland.

\section{Study protocol}

The study was a reference-controlled cross-over trial. The current data are part of a study that examines the effect of different diets on fuel metabolism and exercise capacity. Peak oxygen consumption $\left(\mathrm{O}_{2}\right.$ peak) was determined by an incremental exercise test on a cycloergometer until exhaustion (Ergometrics 900, Ergoline, Bitz, Germany, and Oxycon B, Jäger, Höchberg, Germany). The subjects started at a workload of $100 \mathrm{~W}$ for $2 \mathrm{~min}$, after which the workload was increased each $2 \mathrm{~min}$ by $30 \mathrm{~W}$. Heart rate was continuously monitored. The dietary treatment was preceded by a 3-day run-in period. Subjects kept a food diary and records on physical activity during this period in order to duplicate diet and physical activity before the second trial. After the run-in phase, subjects underwent a 3 -h supervised exercise session at $\sim 50 \% \mathrm{~W}_{\max }$ to reduce body energy stores before adhering to a strict diet treatment for 2.5 days with physical activity limited to sedentary occupations. HF or LF diet was provided in prepackaged meals in a random order. LF diet consisted of $0.5 \mathrm{~g}$ fat $/ \mathrm{kg} \mathrm{BW}$ per day for 2.5 days; HF diet included $0.5 \mathrm{~g}$ fat $/ \mathrm{kg} \mathrm{BW}$ per day for 1 day (three meals) followed by $3.5 \mathrm{~g}$ fat $/ \mathrm{kg}$ BW per day for 1.5 day (four meals). Protein and carbohydrate content was identical in both diets (carbohydrate: $7 \mathrm{~g} / \mathrm{kg}$ BW per day; protein: $1.2 \mathrm{~g} / \mathrm{kg}$ BW per day). The energy content was $38 \mathrm{kcal} / \mathrm{kg}$ BW per day, except for the last 1.5 days of fat supplementation on the HF diet, where it was higher ( $68 \mathrm{kcal} / \mathrm{kg}$ BW per day). Mean calorie intake during LF diet was adjusted to the requirements per weight of men (30), that is, about $2850 \mathrm{kcal} /$ day, whereas the 1.5-day HF diet included a calorie intake of $5000 \mathrm{kcal} /$ day, indicating overfeeding. The diet was prepared at the Nestlé Research Centre (Lausanne, Switzerland).

After an overnight fast, the subjects attended the endocrine ward at $0800 \mathrm{~h}$. A standardized breakfast consisting of $50 \mathrm{~g}$ carbohydrates was ingested (100 g white bread snack), and $2.5 \mathrm{~h}$ later an indwelling cannula was placed in a forearm vein for blood sampling and perfusion of physiologic saline solution $(\mathrm{NaCl} 0.9 \%)$. Pre-exercise blood samples were drawn 15 min later, and the subjects rested for $30 \mathrm{~min}$. The standardized exercise was performed on a cycloergometer (Ergometrics 900, Ergoline, Bitz, Germany). It comprised a constant work rate of $50 \% \mathrm{~W}_{\max }$ for $3 \mathrm{~h}$. Blood samples were taken at regular interval throughout the 3-h exercise (after 15, 45, 80, 110, 130, 150 and $180 \mathrm{~min})$. Blood samples were centrifuged at $4{ }^{\circ} \mathrm{C}$ and $290 \mathrm{~g}$ for $10 \mathrm{~min}$, and plasma and serum samples were stored at $-70{ }^{\circ} \mathrm{C}$ until further processing. Dehydration during the exercise test was offset by infusion of physiologic saline solution $(1.0 \pm 0.2 \mathrm{l})$ and regular ingestion of water $(1.9 \pm 0.2 \mathrm{l})$. Body weight was measured before and after the exercise test on an electronic balance (Seca; Cosmos c/o B. Schild, Biel, Switzerland). Subjective perception of fatigue was assessed with the 6-20 Borg scale (31). An identical protocol was performed 2-6 weeks apart with HF and LF diet respectively. 


\section{Measurements of hormones}

Total plasma ghrelin levels were measured with a commercially available RIA (Phoenix Pharmaceuticals, Belmont, CA, USA). The interassay coefficient of variation (CV) was $13.6 \%$, and the intra-assay CV was $5.3 \%$. Serum GH concentrations were determined with an enzymatically amplified, two-step sandwich immunoassay (Diagnostic System Laboratories, Webster, TX, USA). The interassay CV was $6.5 \%$, and the intraassay CV $4.3 \%$. Serum IGF-I levels were quantified by an immunoradiometric assay (Nichols Institute Diagnostics, Paris, France; interassay CV 9.3\%, intra-assay CV 4.6\%). Plasma insulin and cortisol were measured by ELISA enzyme immunoassays (MG59011 and RE52061, Immuno-Biological Laboratories, Hamburg, Germany). Plasma leptin was measured by RIA (LEP R40, Mediagnost, Reutlingen, Germany).

\section{Measurements of metabolites}

Triglycerides (TG) and glucose concentrations were determined by enzymatic tests (BioMérieux 61.236, Geneva, Switzerland) on a Cobas Mira centrifugal analyzer (Roche). Plasma free fatty acid (FFA) concentrations were quantified in duplicate by gas chromatography (Hewlett Packard 6890, Palo Alto, CA, USA) after conversion to their methylesters.

\section{Data presentation and statistical analysis}

The integrated area under the curve (AUC) of hormones and metabolites was calculated by the trapezoidal method. Pre-exercise concentrations of normally distributed metabolites and hormones were expressed as mean \pm S.E.M. Known not normally distributed variables (pre-exercise TG concentrations and AUC values) were expressed as median and interquartile range (IQR). The effect of exercise on hormone and metabolite concentrations was estimated by a test for repeated measures (ANOVA; SPSS, Chicago, IL, USA). The effect of diet was analyzed by comparing AUC of metabolites and hormones after LF and HF diets. Normally distributed variables were analyzed by paired t-test; not normally distributed variables by nonparametric testing (Wilcoxon rank test). A $P$ value of $<0.05$ was considered significant.

\section{Results}

\section{Subjects}

The general characteristics of the subjects are summarized in Table 1. All athletes were endurance trained and were studied in a period without competition. The maximum power was $365 \pm 29 \mathrm{~W}$ with a maximum heart rate of $186 \pm 9$ beats/min. Body weight did not significantly change during the 3-h exercise tests, and
Table 1 Clinical characteristics and exercise variables of 11 endurance-trained male athletes.

\begin{tabular}{lr}
\hline Age (years) & $31.4 \pm 1.7$ \\
Weight $(\mathrm{kg})$ & $74.5 \pm 2.5$ \\
$\mathrm{BMI}\left(\mathrm{kg} / \mathrm{m}^{2}\right)$ & $22.6 \pm 0.5$ \\
Lean body mass $(\mathrm{kg})$ & $68.8 \pm 2.1$ \\
Fat mass $(\mathrm{kg})$ & $7.6 \pm 0.6$ \\
$\mathrm{VO}_{2}$ peak $(\mathrm{ml} / \mathrm{kgper} \min )$ & $63.3 \pm 2.2$ \\
$50 \%$ of $\mathrm{W}_{\max }(\mathrm{W})$ & $183 \pm 4.2$
\end{tabular}

Values are mean \pm S.E.M. $\quad V_{2}$ peak $=$ aerobic capacity. $W_{\max }=$ maximal power at $\mathrm{VO}_{2}$ peak.

heart rate was not significantly different during exercise after HF and LF diet. The perceived exertion according to the Borg scale (31) was not significantly different after $\mathrm{HF}$ and LF diet.

\section{The effect of diet on hormone levels before and during exercise (Table 2 and Figs 1-5)}

Pre-exercise (baseline) ghrelin levels were not significantly different after LF and HF diet. LF diet resulted in a significantly higher AUC of ghrelin concentrations during exercise than HF diet $(P<0.03)$ (Fig. 1). Preexercise GH concentrations were significantly lower after LF than HF diet $(P<0.02)$. Diet did not significantly affect AUC of GH levels during exercise (Fig. 2). HF or LF diet did not significantly modify pre-exercise IGF-I concentrations $(P=0.45)$. Pre-exercise levels of leptin were significantly lower after LF than HF diet $(P<0.02)$. LF diet induced a significant reduction in AUC of leptin levels during exercise compared with HF diet $(P<0.02)$ (Fig. 3). Pre-exercise cortisol concentrations were not statistically different after either diet. Diet did not significantly modify AUC of cortisol levels during exercise (Fig. 4). Pre-exercise insulin levels were not significantly different after either diet. LF diet resulted in a significant decrease in AUC of insulin concentrations during exercise compared with HF $\operatorname{diet}(P<0.02$; Fig. 5$)$.

\section{The effect of exercise on hormone concentrations (Figs 1-5)}

The 3-h exercise resulted in a significant increase in ghrelin concentrations after LF $(P<0.001)$ and HF $(P<0.001)$ diets. Maximal ghrelin levels were observed during the last hour of exercise after the LF and the HF diets (Fig. 1). GH levels significantly increased during exercise after LF $(P<0.001)$ and HF $(P<0.001)$ diets. Maximal GH concentrations occurred after 45-min exercise and then declined steadily after both diets (Fig. 2). Exercise induced a small but significant decrease in leptin concentrations after the LF diet during the last hour of exercise $(P<0.03)$, whereas no significant change of leptin 
Table 2 Exercise-induced hormone concentrations after low-and high-fat diet in 11 endurance-trained male athletes.

\begin{tabular}{|c|c|c|c|}
\hline & Low-fat diet & High-fat diet & $P$ value \\
\hline \multicolumn{4}{|l|}{ Pre-exercise concentrations } \\
\hline Ghrelin (pg/ml) & $406.9 \pm 41.0$ & $400.5 \pm 32.0$ & 0.86 \\
\hline $\mathrm{GH}(\mathrm{ng} / \mathrm{ml})$ & $0.27 \pm 0.08$ & $1.18 \pm 0.42$ & 0.02 \\
\hline Leptin (ng/ml) & $0.69 \pm 0.06$ & $0.83 \pm 0.09$ & 0.02 \\
\hline Cortisol ( $\mu \mathrm{g} / \mathrm{l})$ & $141.0 \pm 15.9$ & $155.5 \pm 16.7$ & 0.14 \\
\hline Insulin ( $\mu \mathrm{U} / \mathrm{l})$ & $4.9 \pm 0.9$ & $10.3 \pm 2.7$ & 0.15 \\
\hline IGF-I (ng/ml) & $169 \pm 13.3$ & $163 \pm 10.6$ & 0.45 \\
\hline \multicolumn{4}{|l|}{ Area under the curve (AUC) } \\
\hline Ghrelin (AUC) (ng/ml per min) & $98.0(72.2-131.6)$ & $91.3(74.4-112.0)$ & 0.03 \\
\hline GH (AUC) $(\mathrm{ng} / \mathrm{ml}$ per min) & $1198(914-1949)$ & $1101(714-2467)$ & 0.89 \\
\hline Leptin (AUC) (ng/ml per min) & $132(115-163)$ & $183(119-212)$ & 0.02 \\
\hline Cortisol (AUC) (mg/l per min) & $25.5(23.2-31.6)$ & $27.8(22.0-34.1)$ & 0.41 \\
\hline Insulin (AUC) ( $\mu$ U/l/ per min) & $151(114-265)$ & $371(244-483)$ & 0.02 \\
\hline
\end{tabular}

For pre-exercise concentrations, values are mean \pm S.E.M. For AUC, values are expressed as median and interquartile range (parentheses).

concentrations was observed after the $\mathrm{HF}$ diet $(P=0.45) \quad$ (Fig. 3). Exercise did not significantly affect cortisol concentrations after the HF diet $(P=0.41)$, but these significantly increased after the LF diet during the last hour of exercise $(P<0.003)$ (Fig. 4). Insulin levels $2.5 \mathrm{~h}$ after a standardized carbohydrate load $(50 \mathrm{~g})$ significantly decreased during exercise after $\operatorname{LF}(P<0.001)$ and $\operatorname{HF}(P<0.001)$ diets (Fig. 5).

\section{The effect of diet on metabolites before and during exercise (Table 3)}

Compared with HF diet, pre-exercise glucose concentrations were not significantly different after LF diet. Diet did not significantly affect AUC of glucose concentrations during exercise. Pre-exercise FFA concentrations tended to be higher after $\mathrm{HF}$ diet without reaching statistical significance $(P=0.08)$. LF diet did

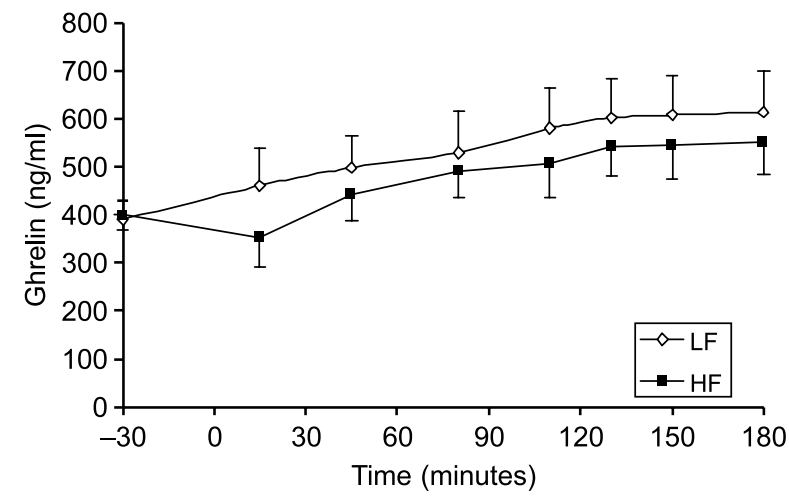

Figure 1 Mean ( \pm S.E.M.) ghrelin concentrations during 3-h exercise at $50 \% W_{\max }$ in 11 endurance-trained male athletes after low-fat (LF) and high-fat (HF) diets. Test of within-subject effects for repeated measures: LF: $P<0.001$; HF: $P<0.001$; pre-exercise ghrelin concentrations LF vs HF: $P=0.86$ (Wilcoxon rank test). not significantly change the AUC of FFA concentrations during exercise compared with HF $(P=0.10)$. Pre-exercise TG concentrations tended to be higher after $\mathrm{LF}$ than $\mathrm{HF}$ diet $(P=0.06)$.

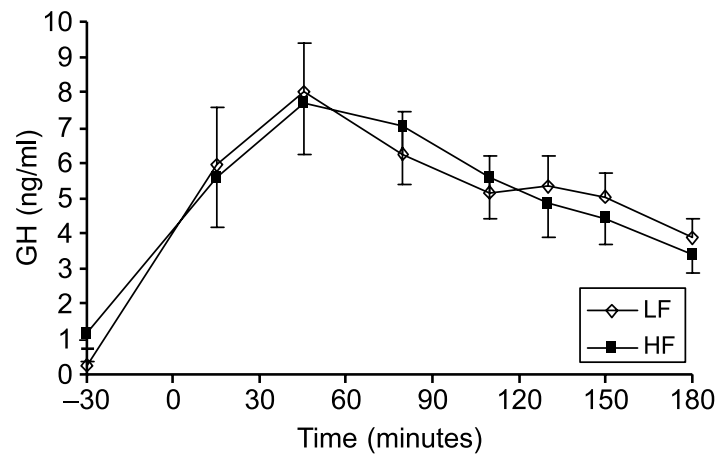

Figure 2 Mean ( \pm S.E.M.) growth hormone (GW) concentrations during 3-h exercise at $50 \% \mathrm{~W}_{\max }$ in 11 endurance-trained male athletes after LF and HF diets. Test of within-subject effects for repeated measures: LF: $P<0.001$; HF: $P<0.001$; pre-exercise GW concentrations LF vs HF: $P<0.02$ (Wilcoxon rank test).

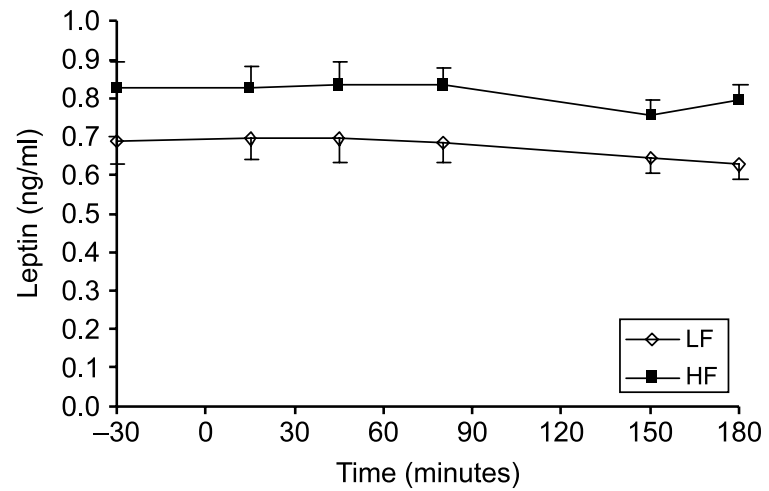

Figure 3 Mean ( \pm S.E.M.) leptin concentrations during 3-h exercise at $50 \% \mathrm{~W}_{\max }$ in 11 endurance-trained male athletes after LF and HF diets. Test of within-subject effects for repeated measures: LF: $P<0.04$; HF: $P=0.421$; pre-exercise leptin concentrations LF vs HF: $P<0.02$ (Wilcoxon rank test). 


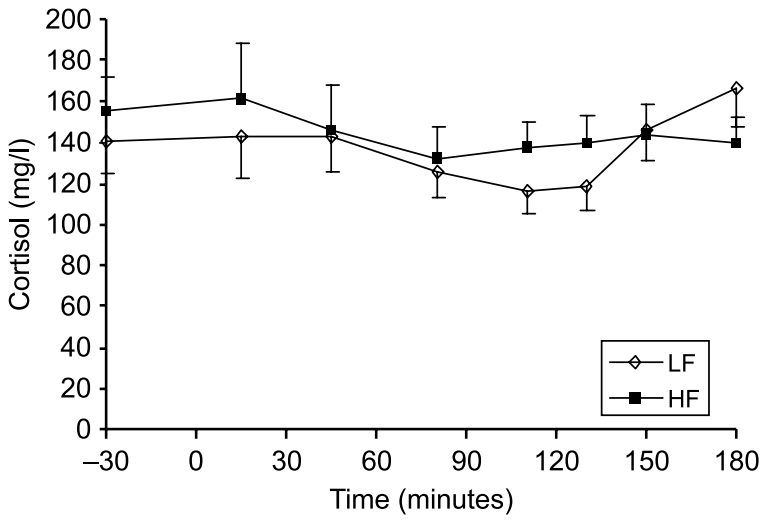

Figure 4 Mean ( \pm S.E.M.) cortisol concentrations during 3-h exercise at $50 \% \mathrm{~W}_{\max }$ in 11 endurance-trained male athletes after LF and HF diets. Test of within-subject effects for repeated measures: LF: $P<0.003$; HF: $P=0.41$; pre-exercise cortisol concentrations LF vs HF: $P=0.14$ (Wilcoxon rank test).

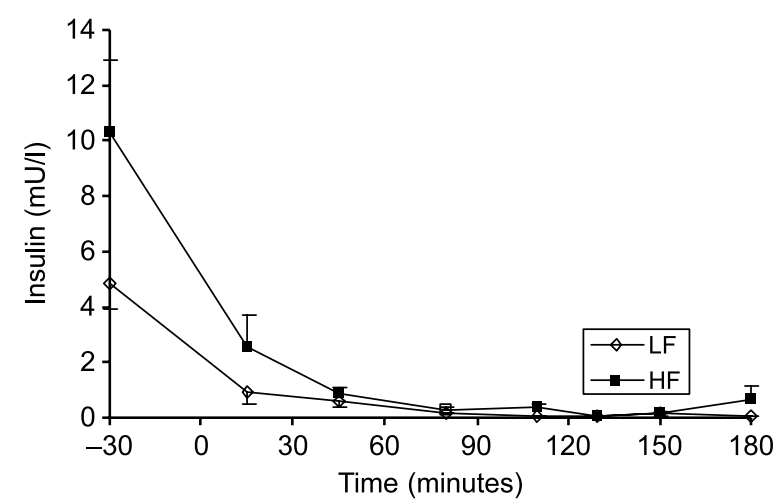

Figure 5 Mean ( \pm S.E.M.) insulin concentrations during 3-h exercise at $50 \% \mathrm{~W}_{\max }$ in 11 endurance-trained male athletes after LF and HF diets. Exercise started $2.5 \mathrm{~h}$ after standardized $50 \mathrm{~g}$ carbohydrate snack. Test of within-subject effects for repeated measures: LF: $P<0.001$; HF: $P<0.001$; pre-exercise insulin concentrations LF vs HF: $P=0.15$ (Wilcoxon rank test).

\section{The effect of exercise on metabolites}

During exercise, glucose concentrations significantly decreased after LF and HF (delta glucose concentrations pre-exercise vs end of exercise: LF: $0.8 \pm 0.3 \mathrm{mmol} / \mathrm{l}$, mean \pm S.E.M.,$\quad P<0.001 ; \quad$ HF: $\quad 0.8 \pm 0.06 \mathrm{mmol} / \mathrm{l}$, $P<0.001)$. The lowest values were within the normal range and were observed during the last hour of exercise (LF: $4.3 \pm 0.3 \mathrm{mmol} / \mathrm{l}$; HF: $4.7 \pm 0.3 \mathrm{mmol} / \mathrm{l})$. Exercise resulted in a significant increase in FFA concentrations after LF and HF (delta FFA concentrations: LF: $1069 \pm 75.3 \mu \mathrm{mol} / \mathrm{l}, \quad P<0.001 ; \quad \mathrm{HF}$ : $965 \pm 86 \mu \mathrm{mol} / \mathrm{l}, \quad P<0.001) . \quad$ FFA concentrations started to rise after 45-min exercise, and maximal FFA concentrations were observed at the end of the exercise (LF: $1147 \pm 72.2 \mu \mathrm{mol} / \mathrm{l}$; HF: $1086 \pm 97.4 \mu \mathrm{mol} / \mathrm{l})$.

\section{Discussion}

The main new finding of this study is that short-term intervention with $\mathrm{HF}$ and LF diets resulted in opposite changes of ghrelin and leptin concentrations during a 3-h aerobic exercise in endurance-trained male athletes.

Effects of diet on pre-exercise hormone concentrations The HF diet resulted in a lower pre-exercise leptin concentration than the LF diet, indicating that short-term (i.e. 1.5-day) diet affects leptin concentration. It is conceivable that the reduced calorie intake with LF diet contributed to this finding. Indirect regulators of leptin, such as insulin or cortisol (9), may be involved in modulating leptin concentrations in this condition, but this was not confirmed by the results of the current study. The LF diet resulted in significantly lower pre-exercise GH concentrations, but IGF-I levels were unchanged. Due to the pulsatile secretion of $\mathrm{GH}$ (32), these findings have to be interpreted with caution. In addition, the mechanism underlying these results remains unclear, since metabolic regulators of $\mathrm{GH}$ secretion were unchanged before exercise (glucose) and are unlikely to explain the current findings (FFA) (12).

In contrast to leptin, ghrelin and cortisol pre-exercise levels were not influenced by diet modality, suggesting that the time course of these peripheral signals of energy homeostasis might be different from leptin.

Effects of diet on hormone concentrations during exercise GH and IGF-I levels were not influenced by diet modality, whereas ghrelin and leptin concentrations

Table 3 Exercise-induced glucose, free fatty acid and triglyceride concentrations after low-and high-fat diet in 11 endurance-trained male athletes.

\begin{tabular}{lccc}
\hline & Low-fat diet & High-fat diet & $P$ value \\
\hline Pre-exercise concentrations & & & 0.23 \\
Glucose $(\mathrm{mmol} / \mathrm{l})$ & $5.2 \pm 0.3$ & $5.5 \pm 0.2$ & 0.08 \\
FFA ( $\mu \mathrm{mol} / \mathrm{l})$ & $77.9 \pm 13.8$ & $11.7 \pm 46.9$ & $0.53(0.38-0.60)$ \\
TG (mmol/l) & $0.72(0.59-0.83)$ & $985(972-1051)$ & 0.06 \\
Area under the curve (AUC) & $974(960-1012)$ & $78.0(52.8-106.1)$ & 0.20 \\
Glucose $(\mathrm{mmol} / \mathrm{l}$ per min) & $98.4(77.9-119.7)$ & 0.10 \\
FFA (mmol// per min) &
\end{tabular}

Normally distributed variables (glucose, FFA) are expressed as mean \pm S.E.M. Not normally distributed variables (TG and AUC) are expressed as median and interquartile range. $\mathrm{TG}=$ triglycerides; $\mathrm{FFA}=$ free fatty acids 
were affected by different diets. LF diet resulted in an increase in ghrelin concentrations, whereas leptin levels were reduced and the inverse results were observed after HF. This further substantiates the concept that hormonal regulation during a constant workload depends on the availability of fuel, which, in turn, is related to the intake of nutrients on the days before exercise. It is tempting to speculate that LF diet may have resulted in lower energy stores, which are rapidly used during exercise. Consequently, peripheral markers of negative energy balance, such as leptin and ghrelin concentrations, significantly change, in order to restore energy balance by increasing appetite and food intake (22). In contrast, HF diet provided a sufficient energy supply to cover more of the energy requirements. Consequently, hormonal signals of energy homeostasis were less apparent. These results extend the observation that energy homeostasis is under tight hormonal control with opposite function for ghrelin and leptin (33). Since the amount of carbohydrate intake was identical within both diets, these findings are probably related to the differences in dietary fat and/or its energy content. Our findings are consistent with a preliminary report in monozygotic twins, which showed, in 'clamped energy balance conditions' (i.e. standardized overfeeding or negative energy balance for 100 days by food restriction), that ghrelin concentrations tend to decrease and leptin to increase in a condition of energy surfeit (i.e. HF diet), whereas the opposite was observed in a state of energy shortage (i.e. LF diet) (34). Several studies have demonstrated that glucose is essential in modulating leptin levels (22). In addition, data on rat adipocytes suggest that insulin-mediated glucose metabolism, and not insulin per se, is critical in increasing leptin secretion (35). The current findings, however, in contrast to previous studies $(23,36)$, suggest that dietary fat affects leptin concentrations. Differences in study protocol and study population are probably responsible for the dissimilar results. Information on the effect of macronutrients on ghrelin levels is limited. Our results are consistent with those of Lee et al. (37), who showed ghrelin plasma levels to be significantly lower in rats fed HF diet than in control rats. However, due to the dietary protocol with different percentages of carbohydrates within the $\mathrm{HF}$ and LF diets, the respective role of these nutrients in regulating ghrelin secretion could not be determined. In healthy human subjects, however, recent evidence suggests (27) that an acute lipid load results in a significant decrease in ghrelin levels.

Effects of diet on metabolites before and during exercise Glucose concentrations were not influenced by the diet modalities. Interestingly, after LF diet, pre-exercise plasma TG concentrations tended to be increased, whereas FFA levels tended to be decreased compared with HF diet. These findings indicate that these metabolites may have a different role in energy supply. The underlying mechanisms remain to be elucidated.
This study has its limitations. A nonexercise control experiment was not performed. It is, therefore, difficult to separate the effects of the exercise itself and the pre-exercise carbohydrate snack. Consequently, the current data have to be interpreted with caution. However, the estimated energy consumption during the exercise period was about $2000 \mathrm{kcal}$. The energy content of the carbohydrate snack was $200 \mathrm{kcal}$ (i.e. 10\% of the energy expenditure). If we assume that the energy balance drives the hormonal response, it is conceivable that the measured hormone profile is mainly related to the exercise-induced energy expenditure. This hypothesis is supported by the fact that the time curve of $\mathrm{GH}$ concentrations during exercise (GH peak occurs at $45 \mathrm{~min}$ ) and absolute $\mathrm{GH}$ values are very similar to data of previous studies (38). In contrast to $\mathrm{GH}$, ghrelin concentrations increased steadily during exercise, reaching a plateau within the last hour of exercise. These findings contrast to the results of Dall et al. (20), who recently reported unchanged ghrelin concentrations during 45-min submaximal exercise in healthy adults. This discrepancy may be due to the differences in study protocol (length of exercise, no pre-exercise snack) and study population (males and females, not endurance-trained athletes) in the previous study. A further limitation of the study is that diets were not equicaloric, a fact which may influence the interpretation of the results. However, the objective of the study was to evaluate the effect of an increase in lipid intake while maintaining carbohydrate intake constant. Keeping diets isoenergetic would have required decreased carbohydrate intake to adjust for the increased lipid intake. As carbohydrate intake has more drastic effects on exercise metabolism than lipid intake (39), increasing calorie intake by the HF diet may still be a better option than increasing lipids and decreasing carbohydrates.

In conclusion, this study demonstrates that the hormones considered to be involved in energy homeostasis (ghrelin, GH, leptin and insulin) respond differently during a state of acute negative energy balance with an increase in ghrelin and $\mathrm{GH}$ and a tendency for a decrease in leptin and insulin. Importantly, the extent of these changes depends on the intake of dietary fat 1.5 days before exercise. These findings add more evidence that hormones can be considered as an interface between energy intake and expenditure, the main function being to regulate metabolism in order to respond adequately to the energy needs of the organism.

\section{Acknowledgements}

We thank all the volunteers for their enthusiasm. In addition, we are grateful to Anny Blondel-Lubrano and Irène Zbinden for analyses of insulin, cortisol, leptin, glucose and TG, and Bernard Decarli for help with the preparation of the diet packages. 


\section{References}

1 Meigs JB, Wilson PW, Nathan DM, D'Agostino RB Sr, Williams K \& Haffner SM. Prevalence and characteristics of the metabolic syndrome in the San Antonio Heart and Framingham Offspring Studies. Diabetes 200352 2160-2167.

2 Ford ES, Giles WH \& Dietz WH. Prevalence of the metabolic syndrome among US adults: findings from the third National Health and Nutrition Examination Survey. Journal of the American Medical Association $2002287356-359$.

3 Kojima M, Hosoda H, Date Y, Nakazato M, Matsuo H \& Kangawa K. Ghrelin is a growth-hormone-releasing acylated peptide from stomach. Nature $1999 \mathbf{4 0 2}$ 656-660.

4 Zhang Y, Proenca R, Maffei M, Barone M, Leopold L \& Friedman JM. Positional cloning of the mouse obese gene and its human homologue. Nature 1994372 425-432.

5 Neary NM, Goldstone AP \& Bloom SR. Appetite regulation: from the gut to the hypothalamus. Clinical Endocrinology $200460153-160$.

6 Tschop M, Smiley DL \& Heiman ML. Ghrelin induces adiposity in rodents. Nature $2000 \mathbf{4 0 7} 908-913$.

7 Wren AM, Seal LJ, Cohen MA, Brynes AE, Frost GS, Murphy KG, Dhillo WS, Ghatei MA \& Bloom SR. Ghrelin enhances appetite and increases food intake in humans. Journal of Clinical Endocrinology and Metabolism 200186 59-92.

8 Fisher JS, Van Pelt RE, Zinder O, Landt M \& Kohrt WM. Acute exercise effect on postabsorptive serum leptin. Journal of Applied Physiology 200191 680-686.

9 Kraemer RR, Chu H \& Castracane VD. Leptin and exercise. Experimental Biology and Medicine 2002227 701-708.

10 Hilton LK \& Loucks AB. Low energy availability, not exercise stress, suppresses the diurnal rhythm of leptin in healthy young women. American Journal of Physiology. Endocrinology and Metabolism 2000278 E43-E49.

11 van Aggel-Leijssen DP, van Baak MA, Tenenbaum R, Campfield LA \& Saris WH. Regulation of average $24 \mathrm{~h}$ human plasma leptin level; the influence of exercise and physiological changes in energy balance. International Journal of Obesity and Related Metabolic Disorders 199923 151-158.

12 Giustina A \& Veldhuis JD. Pathophysiology of the neuroregulation of growth hormone secretion in experimental animals and the human. Endocrine Reviews 199819 717-797.

13 Kanaley JA, Weatherup-Dentes MM, Jaynes EB \& Hartman ML. Obesity attenuates the growth hormone response to exercise. Journal of Clinical Endocrinology and Metabolism 199984 3156-3161.

14 Pritzlaff CJ, Wideman L, Weltman JY, Abbott RD, Gutgesell ME, Hartman ML, Veldhuis JD \& Weltman A. Impact of acute exercise intensity on pulsatile growth hormone release in men. Journal of Applied Physiology 199987 498-504.

15 Pritzlaff-Roy CJ, Widemen L, Weltman JY, Abbott R, Gutgesell M, Hartman ML, Veldhuis JD \& Weltman A. Gender governs the relationship between exercise intensity and growth hormone release in young adults. Journal of Applied Physiology 200292 2053-2060.

16 Sutton J \& Lazarus L. Growth hormone in exercise: comparison of physiological and pharmacological stimuli. Journal of Applied Physiology 197641 523-527.

17 Stich V, de Glisezinski I, Berlan M, Bulow J, Galitzky J, Harant I, Suljkovicova H, Lafontan M, Riviere D \& Crampes F. Adipose tissue lipolysis is increased during a repeated bout of aerobic exercise. Journal of Applied Physiology 200088 1277-1283.

18 Lafortuna CL, Marinone PG, Ottolini S \& Sartorio A. GH responses to a near-maximal exercise training session on-the-field in cyclists. Journal of Endocrinological Investigation 200326 RC12-RC14.

19 Holt RI, Webb E, Pentecost C \& Sonksen PH. Aging and physical fitness are more important than obesity in determining exerciseinduced generation of GH. Journal of Clinical Endocrinology and Metabolism $2001865715-5720$.

20 Dall R, Kanaley J, Hansen TK, Moller N, Christiansen JS, Hosoda H, Kangawa K \& Jorgensen JO. Plasma ghrelin levels during exercise in healthy subjects and in growth hormone-deficient patients. European Journal of Endocrinology 2002147 65-70.
21 Muller AF, Lamberts SW, Janssen JA, Hofland LJ, Koetsveld PV, Bidlingmaier M, Strasburger CJ, Ghigo E \& Van der Lely AJ. Ghrelin drives GH secretion during fasting in man. European Journal of Endocrinology $2002146203-207$.

22 Havel PJ. Peripheral signals conveying metabolic information to the brain: short-term and long-term regulation of food intake and energy homeostasis. Experimental Biology and Medicine 2001226 963-977.

23 Havel PJ, Kasim-Karakas S, Mueller W, Johnson PR, Gingerich RL \& Stern JS. Relationship of plasma leptin to plasma insulin and adiposity in normal weight and overweight women: effects of dietary fat content and sustained weight loss. Journal of Clinical Endocrinology and Metabolism $1996 \mathbf{8 1} 4406-4413$.

24 Havel PJ, Townsend R, Chaump L \& Teff K. High-fat meals reduce 24-h circulating leptin concentrations in women. Diabetes 1999 48 334-341.

25 Cummings DE, Weigle DS, Frayo RS, Breen PA, Ma MK, Dellinger EP \& Purnell JQ. Plasma ghrelin levels after diet-induced weight loss or gastric bypass surgery. New England Journal of Medicine 2002346 1623-1630.

26 Shiiya T, Nakazato M, Mizuta M, Date Y, Mondal MS, Tanaka M, Nozoe S, Hosoda H, Kangawa K \& Matsukura S. Plasma ghrelin levels in lean and obese humans and the effect of glucose on ghrelin secretion. Journal of Clinical Endocrinology and Metabolism 200287 240-244.

27 Greenman Y, Golani N, Gilad S, Yaron M, Limor R \& Stern N. Ghrelin secretion is modulated in a nutrient- and gender-specific manner. Clinical Endocrinology $200460382-388$.

28 Giannoulis MG, Boroujerdi MA, Powrie J, Dall R, Napoli R, Ehrnborg C, Pentecost C, Cittadini A, Jorgensen JO \& Sonksen PH. Gender differences in growth hormone response to exercise before and after rhGH administration and the effect of rhGH on the hormone profile of fit normal adults. Clinical Endocrinology $200562315-322$.

29 Nevill ME, Holmyard DJ, Hall GM, Allsop P, van Oosterhout A, Burrin JM \& Nevill AM. Growth hormone responses to treadmill sprinting in sprint- and endurance-trained athletes. European Journal of Applied Physiology and Occupational Physiology 199672 460-467.

30 World Health Organization. Energy and protein requirements. Technical Report Series 724. Geneva: WHO, 1985.

31 Noble BJ. Clinical applications of perceived exertion. Medicine and Science in Sports and Exercise 198214 406-411.

32 Veldhuis JD. Neuroendocrine control of pulsatile growth hormone release in the human: relationship with gender. Growth Hormone and IGF Research $1998 \mathbf{8}$ (Suppl B) 49-59.

33 Horvath TL, Diano S, Sotonyi P, Heiman M \& Tschop M. Minireview: ghrelin and the regulation of energy balance - a hypothalamic perspective. Endocrinology 2001142 4163-4169.

34 Ravussin E, Tschop M, Morales S, Bouchard C \& Heiman ML. Plasma ghrelin concentration and energy balance: overfeeding and negative energy balance studies in twins. Journal of Clinical Endocrinology and Metabolism 200186 4547-4551.

35 Mueller WM, Gregoire FM, Stanhope KL, Mobbs CV, Mizuno TM, Warden CH, Stern JS \& Havel PJ. Evidence that glucose metabolism regulates leptin secretion from cultured rat adipocytes. Endocrinology 1998139 551-558.

36 Weigle DS, Duell PB, Connor WE, Steiner RA, Soules MR \& Kuijper JL. Effect of fasting, refeeding, and dietary fat restriction on plasma leptin levels. Journal of Clinical Endocrinology and Metabolism $199782561-565$.

37 Lee HM, Wang G, Englander EW, Kojima M \& Greeley GH Jr. Ghrelin, a new gastrointestinal endocrine peptide that stimulates insulin secretion: enteric distribution, ontogeny, influence of endocrine, and dietary manipulations. Endocrinology 2002143 185-190.

38 Stokes K. Growth hormone responses to sub-maximal and sprint exercise. Growth Hormone and IGF Research 200313 225-238.

39 Jeukendrup AE. Modulation of carbohydrate and fat utilization by diet, exercise and environment. Biochemical Society Transactions 200331 1270-1273.

Received 19 October 2005

Accepted 5 December 2005 